\title{
A SIMPLIFIED MODELLING APPROACH FOR THE PRACTICAL ENGINEERING ASSESSMENT OF UNREINFORCED MASONRY STRUCTURES USING LAYERED SHELL ELEMENTS
}

\author{
A. HASSANIEH ${ }^{1 *}$, M. GHARIB ${ }^{2}$ AND M. KING $^{3}$ \\ 1 \\ Corresponding Author. Senior Structural Analyst/Engineer, \\ Taylor Thomson Whitting, 48 Chandos Street, St Leonards, NSW 2065, Australia. \\ Email: amir.hassanieh@ttw.com.au \\ ${ }^{2}$ Senior Structural Analyst/Engineer, \\ Taylor Thomson Whitting, 48 Chandos Street, St Leonards, NSW 2065, Australia. \\ Email: mahdi.gharib@ttw.com.au \\ ${ }^{3}$ Associate Director, \\ Taylor Thomson Whitting, 48 Chandos Street, St Leonards, NSW 2065, Australia. \\ Email: michael.king@ttw.com.au
}

Keywords: Unreinforced Masonry, Seismic Assessment, Nonlinear Analysis, Layered Shell, Heritage.

\begin{abstract}
Unreinforced Masonry (URM) has been extensively used as a construction material in mass structures with predominant compression load paths. Despite its reasonably established performance under gravity actions, it can be quite vulnerable to seismic loading, predominantly due to its limited tensile strength and associated quasi-brittle failure modes. Therefore, a reliable seismic assessment of URM structures, including heritage buildings, is vital to ensure life safety and minimise their risk of collapse. This can assist in implementing effective remedial measures, if required, to ensure desirable performance level in future events. Despite significant advancements in masonry research, practical assessment of URM has always been a challenge for structural engineers due to the complexity of the mechanics and geometry involved. Different modelling approaches have been trialled so far, which are typically based on equivalent frame, discrete and continuum elements in 2D/3D domains. In this paper, a simplified nonlinear model is introduced within the framework of conventional layered shell elements, which can be easily implemented in commonly used FE packages, e.g. ETABS and SAP2000. In this model, the URM shell element comprises three layers accounting for cohesion and axial-frictional behaviour parallel and perpendicular to the bed joints, where the mechanical properties can be adjusted for various masonry configurations. The performance of the proposed model is validated against several experimental tests available in the literature, where a good correlation with test data is achieved across various design scenarios and loading conditions.
\end{abstract}




\section{INTRODUCTION}

Masonry is one of the oldest construction materials in the world, which has widely been used in buildings, especially low-rise commercial and residential buildings, in different sizes, shapes, and materials. Unreinforced Masonry (URM) is the simplest form of masonry construction and while it is well suited for bearing gravitational loads, it is prone to lateral loads and foundation differential settlement, mainly due to its limited tensile capacity and ductility.

The analysis of URM buildings is a challenging procedure due to geometrical and mechanical complexities, uncertainties associated with material properties, and possible imperfections and cracking in existing buildings. Masonry, by its nature, is a heterogeneous material, and its overall behaviour is characterised by its three constituent components, namely blocks, mortar, and the bond between them [1]. The compressive strength of blocks and mortar is usually higher than their tensile strength. The bond behaviour in shear comprises cohesion and friction mechanisms, while the tensile behaviour is cohesion-only, and generally, the bond strength is weaker than block and mortar. These result in an anisotropic material, where elastic properties, strengths, and post-peak behaviour are directional dependent.

In past studies, significant efforts have been dedicated to the investigation of masonry behaviour through experimental testing. The mechanical properties and failure mechanisms can be assessed at the scale of the masonry components (block, mortar and bond) [2] and structural elements [3]. The experimental tests have been performed on masonry components [4], wallets [5], masonry walls [6], and full-scale masonry structures [7]. It should be noted that the

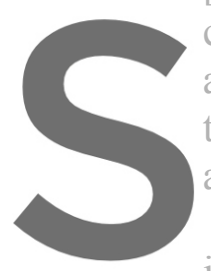
complexities associated with masonry structures extend b
alone, and also depend heavily on the structural details and lay
to horizontal diaphragms, the diaphragms flexibitity, and inte
all significantly affect the behaviour of URM [8].
In conjunction with experinental testing, there has been gr in developing Finite Element (FE) modelling strategies of et. al. [1] categorised the modelling techniques into four groups, namely, (a) block- (b)

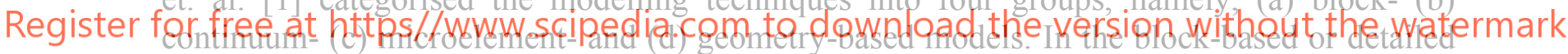

discrete models, the brick is modelled by block and the mortar is modelled by either an element or a contact behaviour. This model can demonstrate clear representation of failure modes, interaction between simultaneous in-plane and out-of-plane loading, but it requires extensive computational demand. It is generally used for experimental validations and the calibration of standard design equations, making it less suitable for engineering design and assessment of fullscale structures [9], [10]. In the smeared continuum approach, the masonry walls are modelled by a continuum body, in which there is no need to use small mesh discretisation and the mesh size can be larger than the actual block/mortar size by utilising homogeneous constitutive laws. In its preliminary versions, it was assumed that the masonry has no tensile capacity, and a linearelastic behaviour was assumed for compression [11], [12]. In advancement of this approach, some nonlinear constitutive laws have been proposed based on fracture mechanics, damage mechanics and/or plasticity methods [13], [14]. Several failure criteria have been formulated and utilised for masonry behaviour such as tension cut-off, Coulomb friction, and a compressive cap criterion [15]. Each criterion has been employed to capture a specific failure mode of masonry. The continuum-based methods have been widely used in the modelling of historical masonry buildings, which usually have complex geometry [1]. Despite the variety of the 
material models developed in the literature, only some have been successfully validated and implemented in available advanced finite element software, such as DIANA and ABAQUS. In the microelement (lumped plasticity) models, the focus is mainly on global seismic behaviour of the structure. In this method, each wall segment may be categorised as either a pier or a spandrel, whereby piers are akin to columns and carry vertical and lateral loads simultaneously, and spandrels span between two adjacent piers and act more like beams. In this method, linear elastic frame elements have been utilised to model the piers and spandrels, then nonlinear hinges are assigned locally to the member to capture the inelastic behaviour as lumped plasticity [16], [17]. Although the concept of lumped plasticity is simpler and readily incorporated in the common commercial analysis software such as ETABS [18] and SAP2000 [19], it has its own drawbacks. For example, its applications to buildings with arbitrary perforations/openings forming irregular stacks of wall piers and spandrels may not be a straightforward task. Also, it requires some initial indication of the loading, such as the level of axial compression in the member, to properly define the friction properties of the representative shear hinges. Thereby, the distributed plasticity approach in such cases may have a clear advantage over the lumped plasticity approach. In geometry-based models, the structure is modelled as a rigid body. Typically, this kind of modelling is useful to assess equilibrium and collapse mechanics of URM walls [20], [21], but can fall short in capturing masonry behaviour in a progressive loading scenario.

The development of a simplified yet reasonably accurate constitutive framework for the modelling of orthotropic behaviour of masonry structures in commonly used commercial analysis software (e.g. engineers and the build appropriate utilisation piers, spandrels and eyer followed by its implamentation in analysis software packag against several experimental studies available in the literature.
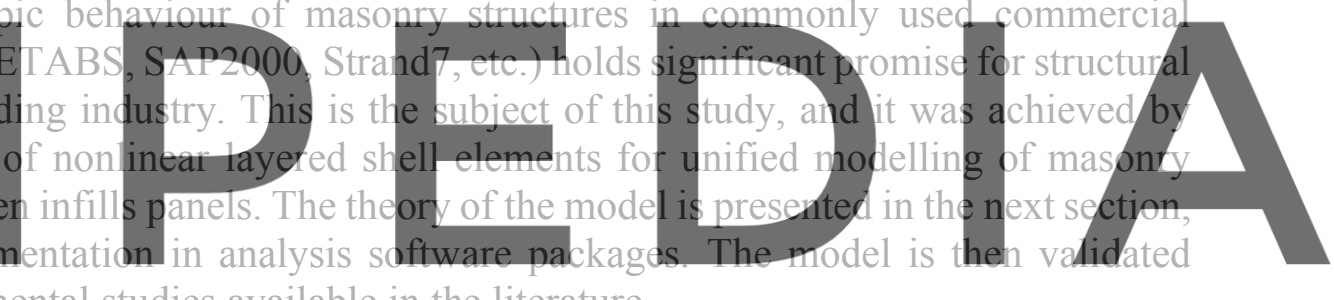

Register for free at https//www.scipedia.com to download the version without the watermark 2 MATERIAL MODEL

The structural capacity of historical masoniry structures has been generally assessed based on design equations and prescriptive provisions in the international design standards using linear elastic analysis in commercial finite element analysis software. With the introduction of performance-based analysis and design concepts for seismic assessment of existing structures and their successful incorporation into some international provisions by FEMA[22], ASCE [23] and NZSEE [24], explicit nonlinear modelling of historical buildings holds significant merit in the building industry to assess their structural performance under different earthquake records and hazard levels using nonlinear static (Pushover) or dynamic (Time-history) analysis methods. This objective has been achieved by either modelling concentrated/lumped plasticity in potential plastic hinge regions within the members, or by explicit inelastic constitutive modelling commonly known as distributed plasticity. The available guidelines and provisions typically cover the former by characterising nominal plastic hinge properties and performance levels for different actions and members, whereas the latter has been more extensively covered in academic research.

Bed joint sliding is one of the common modes of shear failure in squat piers of low aspect 
ratio, which is typically expressed in design standards by a Mohr-Coulomb failure criterion as shown in Figure 1, which is a function of bond and frictional resistance and considered to be a displacement-controlled mode due to the relatively ductile residual component from the sustained friction. The conventional Mohr-Coulomb failure criterion is capped with straight cut-offs limits in tension and/or compression; however, a more realistic criterion would include curved tension/compression caps to account for the possible interactions at high axial stress levels such as that between shear friction and axial compression at high compressive stress states. This results in a reduced frictional component for a combined high axial compression and interface shear stress levels, which can be alternatively expressed by an idealised linear compression cap with a representative slope $(\psi)$ when axial compression stress exceeds a critical limit $\left(\sigma_{\mathrm{c} . l i m}\right)$. In lieu of a refined assessment, the so-called dilatation angle may be approximated as $\psi=(\pi-2 \varphi) / 4$ for a lower bound limit state analysis as given in [25], [26]. On the tension side, a sustained level of cohesion is generally considered for design purposes in international standards [23],[24], which is typically considered as c/2, and the failure line in Figure 1 is thus replaced with the dashed line intersecting the horizontal axis at $\mathrm{f}_{\mathrm{t}}=\mathrm{c} /(2 \mu)$. A similar shear failure mode may also be observed in short spandrels, but the friction component arises from internal actions due to end restraints and/or externally applied load or prestress (if present). However, axial compression can be generated at high chord rotations upon spandrel cracking and degradation of the cohesion mechanism due to the restraints for geometric deformations and the confinement provided by the neighbouring piers. An upper bound

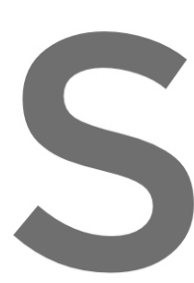
estimate for this residual clanp

state associated with the
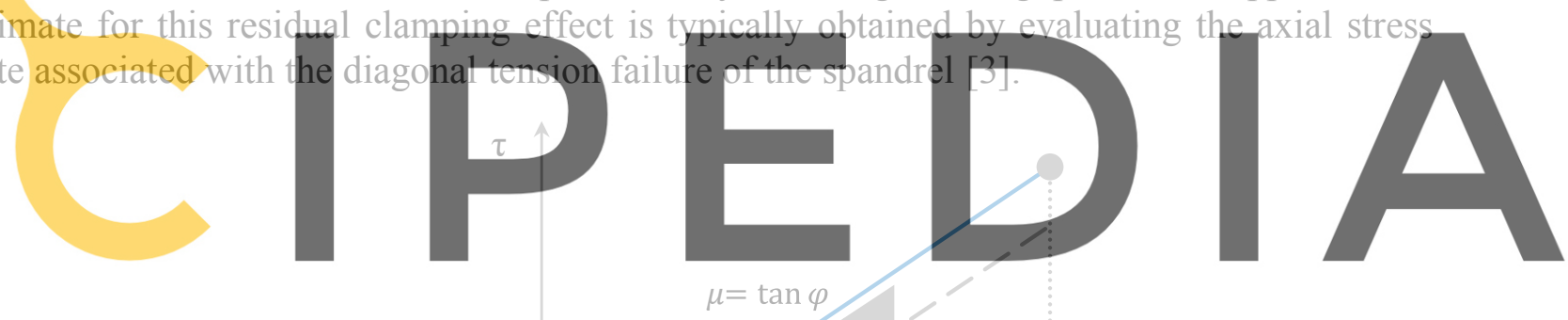

Register for free at https//www.scipedia.com to download the version without the watermark

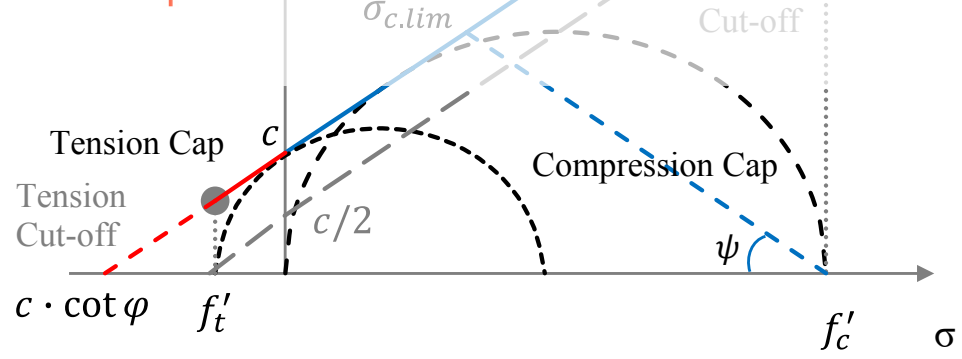

Figure 1 :An adjusted Mohr-Coulomb failure criterion to represent the shear fraction behaviour

In slender piers with high aspect ratio, flexural behaviour is expected to dominate the overall response, which manifests as flexural tensile cracking along the bed joint and typically a rocking mechanism in lightly loaded piers as flexural overturning mode about the toe with an uplift over the heel. This mode is commonly considered to be ductile due to the inherent ductility and prevalent signs of distress. For wall piers with high levels of axial compression, toe crushing may govern the scenario, although it may also be observed at later drift stages of a rocking pier due to the second-order effects. This failure mode is categorised as a brittle mode, 
associated with the crushing of the material in a biaxial stress state over the compression stress block zone. The final failure mode under consideration is the diagonal tension cracking in spandrels and even piers, which can appear either in a stair-stepped cracking pattern through mortar, and/or a diagonal cracking pattern through fractured bricks when mortar is stronger. This failure mode is expected to be triggered in piers of intermediate aspect ratio and initiated at half-height of the wall section. Diagonal tension cracking is also considered to be a forcecontrolled failure mode.

For this study, the commercial FEA software package ETABS was selected for the implementation of the proposed material model due to its common and globally widespread use by structural design engineers, and the contribution of this study to engineering practice is due in part to this fact. The numerical model is implemented using the nonlinear continuum layered shell elements, which make use of properly calibrated directional behaviours to capture the anisotropic behaviour of unreinforced masonry with a reasonable level of accuracy. The proposed framework is equally applicable to SAP2000 or similar FEA software supporting nonlinear layered shell elements with frictional behaviour.

For the axial-flexural response of the masonry elements, it is expected that the adaptation of directional shell layers with representative uniaxial stress-strain curves for different orthogonal material directions, i.e. horizontal and vertical directions for a regular bond pattern, should be able to reasonably capture the expected behaviour and associated failure modes such as toe crushing and rocking in piers, and flexural cracking in long spandrels. This acts like a Rankine (maximum stress) failure criterion for limiting the compressive and tensile capacity in different material directions and stress quadrants, and
favourable effect of confinement in a biaxial
response include a shear friction component
resistance due to clamping from normal comp layer is included to represent the cohesive
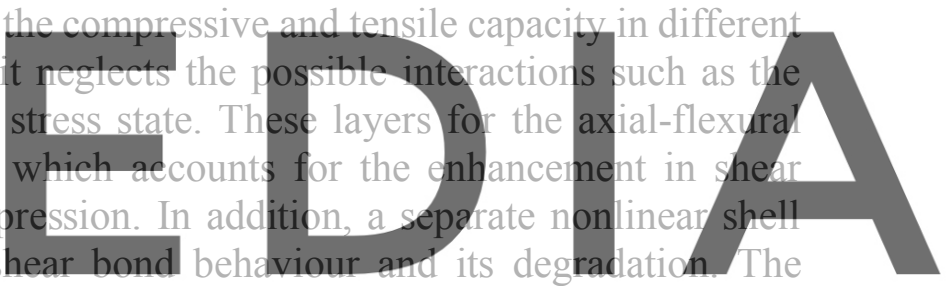

summation of these layers aims to capture the shear response including bond and frictional

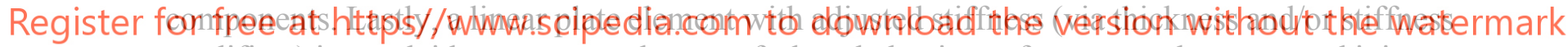
modifiers) is overlaid to represent the out-of-plane behaviour of masonry elements, and it is not intended to precisely capture the interactions between in-plane and out-of-plane behaviours if relied upon.

A nonlinear stress-strain curve is considered as shown in Figure 2 for representing the uniaxial behaviour in each direction, which is in line with the recommendations in Eurocode 6 [27]. The behaviour in tension is assumed to be linear elastic up to the masonry's tensile cracking capacity, followed by linear strain-softening depending on the fracture energy and the characteristic length of the FE elements where strain localization occurs. If desired, the linear degradation may be replaced with a bilinear softening that can better resemble an exponential decay. An elastic perfect plastic (EPP) curve may be assumed as a simplified alternative (also shown in Figure 2) for both components, to improve the computational cost and convergence, where the idealised curve is established based on the concept of equivalent strain energy up to the ultimate strain capacity. As can be seen, the equivalent bilinear curve in compression has adjusted initial stiffness and peak compression capacity and requires strain limits (e.g. maximum allowable crushing strain) in place to assess the state of crushing at various structural performance levels. The bilinear tensile behaviour essentially assumes a sustained level of tensile capacity as an idealised yield capacity, which is considered to be half of the peak flexural 
tensile capacity in each direction. The vertical tensile capacity $\left(\mathrm{f}_{\mathrm{tv}}\right)$ is generally small due to the horizontal bed joints, and it can be approximated by $\mathrm{f}_{\mathrm{tv}} \approx 0.5 \mathrm{c}_{\mathrm{bj}} / \mu$ according to Figure 1 , where $\mathrm{c}_{\mathrm{bj}}$ is the masonry bed-joint cohesion and $\mu$ is the friction coefficient. However, it is generally neglected for design purposes, especially for a long-term analysis where the formation of cracks along bed joints is highly probable. In contrast, the nominal horizontal tensile capacity $\left(\mathrm{f}_{\text {th }}\right)$ can be significantly higher due to the stair-stepped pattern of the masonry bond and tensile cracking, which in the absence of vertical compression over the bed joint may be approximated as $\mathrm{f}_{\mathrm{th}} \approx 0.5 \mathrm{c}_{\mathrm{hj}} / \mu+\alpha_{\mathrm{s}} \mathrm{c}_{\mathrm{bj}}$, where $\mathrm{c}_{\mathrm{bj}}$ is the masonry head-joint cohesion and $\alpha_{\mathrm{s}}$ is the bond pattern factor taken as the ratio of the sum of horizontal crack length to the sum of vertical crack length.

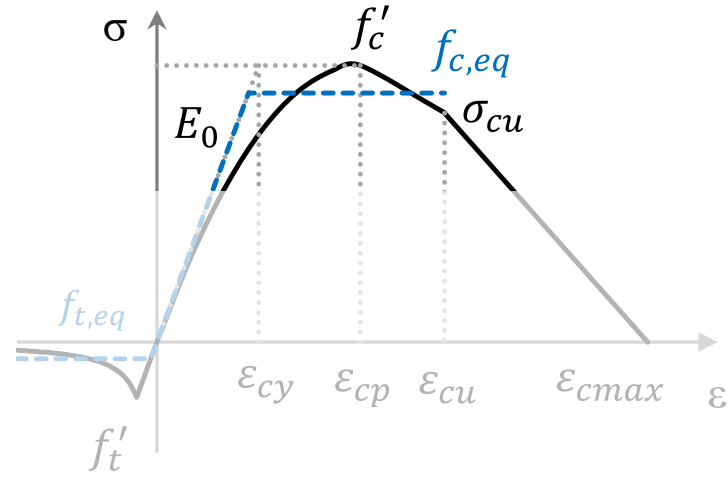

Figure 2 : Schematic illustration of the full and simplified stress-strain curves for uniaxial behaviour in
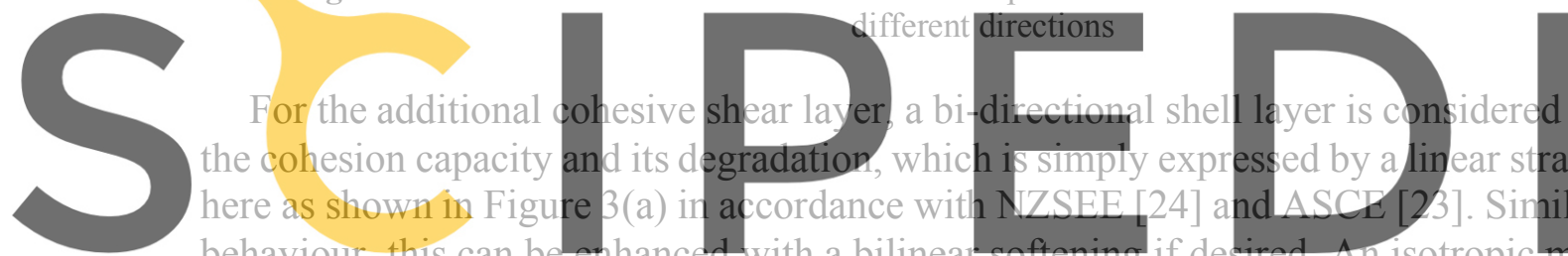

behaviour, this can be enhanced with a bilineal so

a stress-strain curve per Figure 3(b) must be defined in ETABS such that the desired masonry

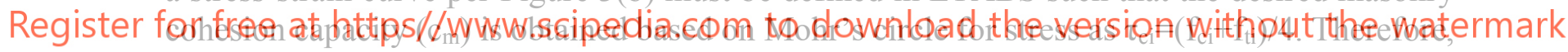

pseudo tensile and compressive capacities are defined as $\mathrm{f}_{\mathrm{ci}}=\mathrm{f}_{\mathrm{ti}}=2 \mathrm{c}_{\mathrm{m}}$ as per Figure $3(\mathrm{~b})$ to

capture the target capacity, noting that the initial stiffness must also be adjusted accordingly such that the resultant shear curve yields the expected shear stiffness.

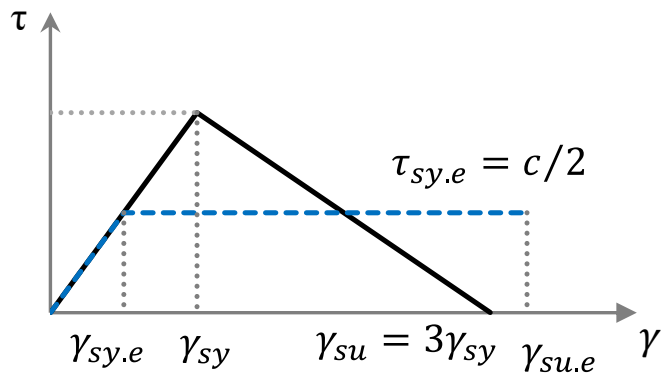

(a) cohesion behaviour

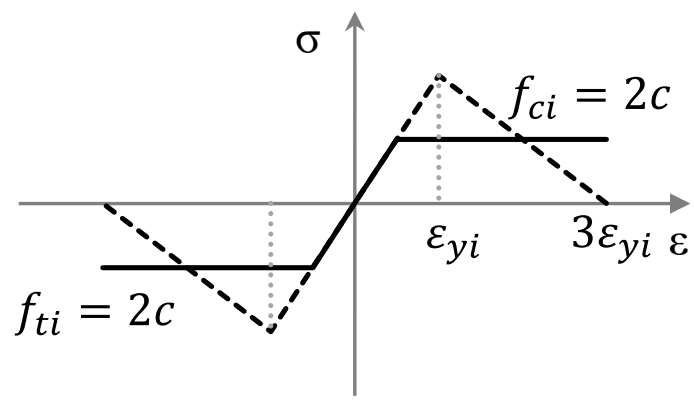

(b) shear layer in ETBAS

Figure 3 : Stress-strain curves for the nonlinear shell layer representing cohesive behaviour

Similar to tensile behaviour, an idealised elastic perfect plastic (EPP) curve with an adjusted maximum allowable strain may be considered as shown in Figure 3(b) to resolve the highly probable convergence issues associated with strain softening and the so-called bifurcation 
problem when using conventional nonlinear solvers and conventional local continuum formulations. When using such a simplified approach, it is essential to assess the strain levels and ensure the limits associated with different performance levels are not exceeded. This can be checked either locally or globally by the engineer, where the latter for example can be assessed in ETABS by the aid of computational strain gauges for piers and spandrels.

The combination of cohesive and frictional layers is expected to capture the overall shear response as schematically illustrated in Figure 4 and characterised in some international standards, e.g. [23], [24]. The directional layers represent the axial-flexural behaviour. The tensile capacity of the directional layers (if defined properly), alongside the frictional demand, is expected to characterise the orientation of principal stress/strain planes and define the principal tensile stress and the diagonal tension capacity. The probability for this failure mode can be visualised by the contour plots for the principal tensile strain ( $\varepsilon_{11}$ or $\left.\varepsilon_{\max }\right)$, whereas the corresponding capacity can be inspected by the overall principal tensile stress plot $\left(\sigma_{11}\right.$ or $\left.\sigma_{\max }\right)$ which is visualised in ETABS by the contour plot for the resultant principal force $F_{\max }$ per unit thickness $\left(\sigma_{\max }=\mathrm{F}_{\max } / \mathrm{t}_{\mathrm{w}}\right)$. Nevertheless, the diagonal tensile capacity $\left(\mathrm{f}_{\mathrm{dt}}\right)$ as a force-controlled component is separately assessed over the course of the analysis by checking the associated shear capacity $\left(\mathrm{V}_{\mathrm{dt}}\right)$ and drift limits for various members (piers/spandrels) in accordance with the available design equations in ASCE [23] and NZSEE [24].
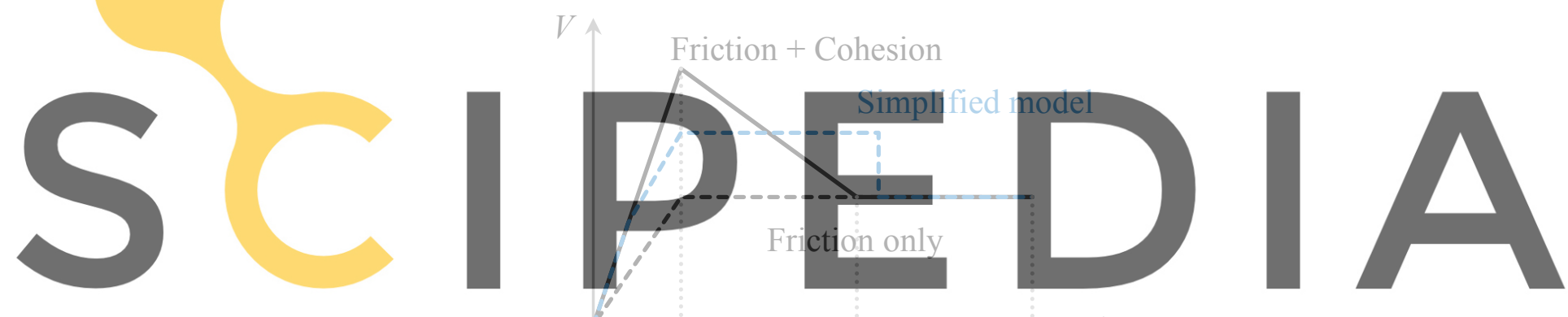

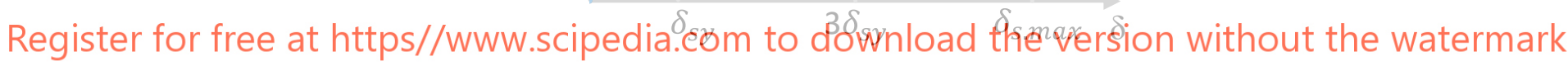

Figure 4 : Overall shear capacity of the member combining cohesive and frictional components

\section{VALIDATIONS}

In this section, the proposed model has been validated against experimental test results available in the literature including a solid URM wall, a perforated URM a URM wall prototype subjected to footing settlement, and a two-storey frame building under lateral loading.

\subsection{Manzouri Tests}

Manzouri et. al. [6] performed lateral loading tests on solid and perforated URM walls, specimens $\mathrm{W} 3$ and $\mathrm{W} 4$, which were subjected to 0.59 and $0.48 \mathrm{MPa}$ overburden, respectively. The mean material properties are provided in Table 1 . The aspect ratio of the solid wall was 0.6 and the walls consisted of three wythes of bricks. The walls were modelled in ETABS with the support and loading conditions consistent with the experimental tests. As can be seen in Figure 5, load-displacement responses of the FE simulation show a good correlation with the experimental results. Also, the principal tensile strain contours, as indications of crack locations 
and patterns, reasonably agree with the reported crack pattern (See Figure 6 and Figure 7). Due to the unidirectional nature of the nonlinear static analysis performed, it is noted that the combination of expected crack patterns for push in positive and negative directions shall be considered for a better comparison with the experimental pattern from cyclic loading. Toe crushing and diagonal tension cracking were captured in specimen \#3, whereas rocking with bed joint sliding were identified in specimen \#4.

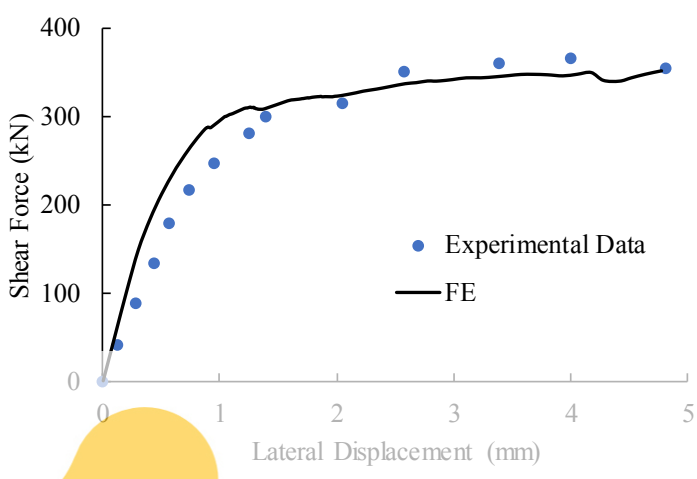

(a)

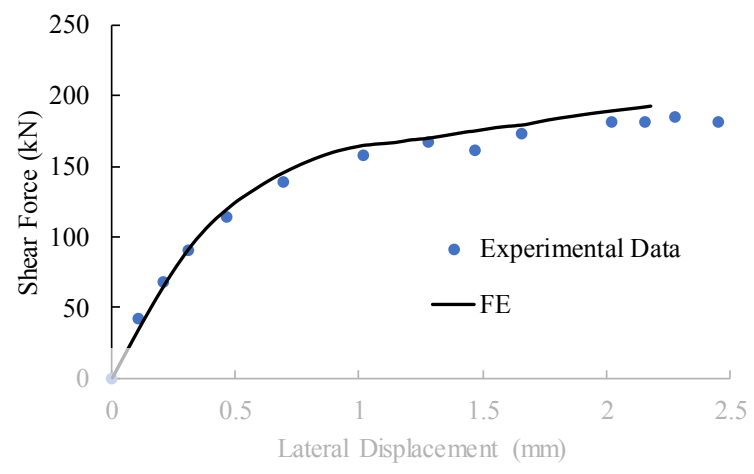

(b)

Figure 5 : Load-displacement of Manzouri tests [6] for W3 and W4 Specimens
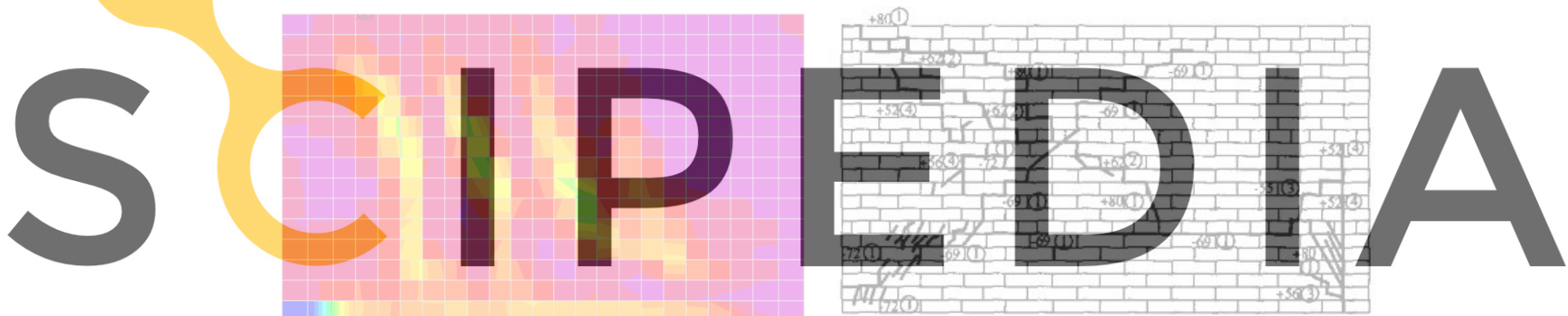

Register for free at https//www.scilpedia.com to download the verrsion without the watermark Figure 6 : Tensile strain contour and crack pattern in experimental tests, specimen W3

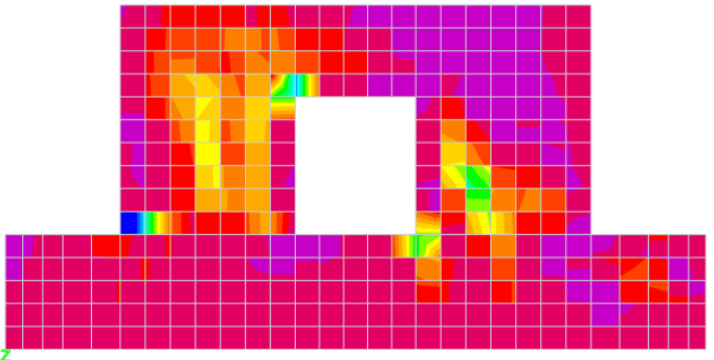

(a)

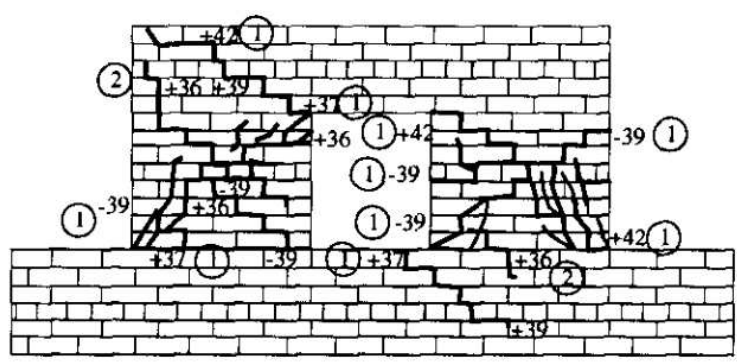

(b)

Figure 7 : Tensile strain contour and crack pattern in experimental tests, specimen W4

Table 1 : mean mechanical properties of tested masonry in Manzouri tests [6]

\begin{tabular}{cllllll}
\hline $\begin{array}{l}\text { Masonry Compressive } \\
\text { Strength (MPa) }\end{array}$ & $\begin{array}{l}\text { Mortar } \\
\text { compressive } \\
\text { strength } \\
\text { (MPa) }\end{array}$ & $\begin{array}{l}\text { Brick } \\
\text { compressive } \\
\text { strength } \\
(\mathrm{MPa})\end{array}$ & $\begin{array}{l}\text { Brick } \\
\text { Modulus of } \\
\text { Rupture } \\
(\mathrm{MPa})\end{array}$ & $\begin{array}{l}\text { Brick } \\
\text { Tensile } \\
\text { Strength } \\
(\mathrm{MPa})\end{array}$ & $\begin{array}{l}\text { Initial } \\
\text { Shear } \\
\text { strength } \\
(\mathrm{MPa})\end{array}$ & $\begin{array}{l}\text { Friction } \\
\text { angle }\end{array}$ \\
\hline \#W3 18 \#W4 11.7 & 2.6 & 21.6 & 3.9 & 2.6 & 0.05 & 50 \\
\hline
\end{tabular}




\subsection{Foundation Settlement Test}

The effect of soil settlement due to tunnelling excavation on a masonry façade was investigated using experimental tests and numerical modelling performed in [28], [29]. A scaled 1/10 model of a historic Dutch house, as shown in Figure 8(a), was tested under imposed support settlement. The deflections and crack patterns were captured during the test.

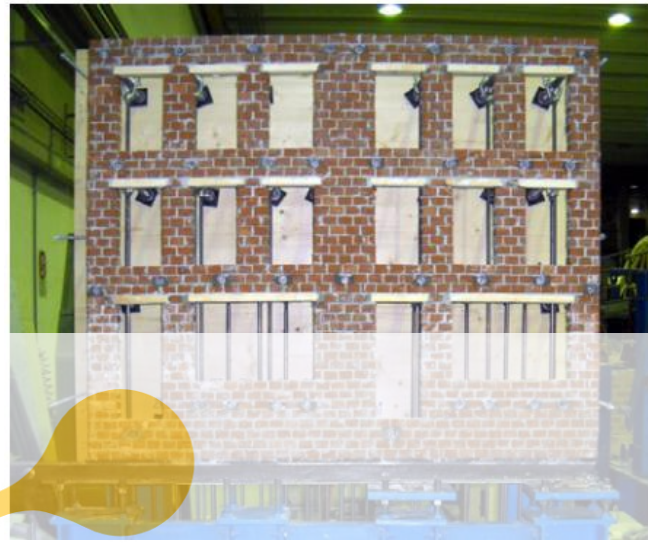

(a)

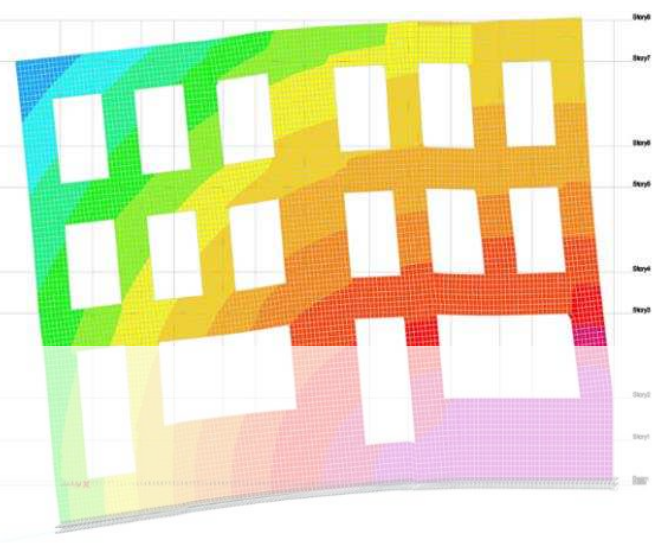

(b)

Figure 8: (a) Scaled specimen test setup and (b) FE model in deformed shape

The mean material properties are listed in

The deformed shap

principal strain is provided in Figure 9/a)

crack pattern from the test as shown in Fig

the initiation and propag

and spandrels over the course of testing.
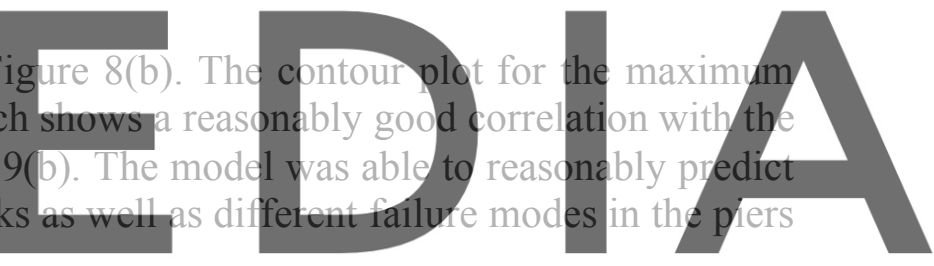

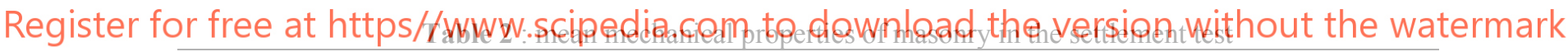

\begin{tabular}{llllll}
\hline $\begin{array}{l}\text { Compressive } \\
\text { Strength (MiPa) }\end{array}$ & $\begin{array}{l}\text { Mortar flexural } \\
\text { strength (MPa) }\end{array}$ & $\begin{array}{l}\text { Mortar } \\
\text { compression } \\
\text { strength (MPa) }\end{array}$ & $\begin{array}{l}\text { Brick } \\
\text { compressive } \\
\text { strength (MPa) }\end{array}$ & $\begin{array}{l}\text { Initial Shear } \\
\text { strength (MiPa) }\end{array}$ & Friction angle \\
\hline 11.4 & 0.31 & 0.62 & 14 & 0.03 & 37 \\
\hline
\end{tabular}

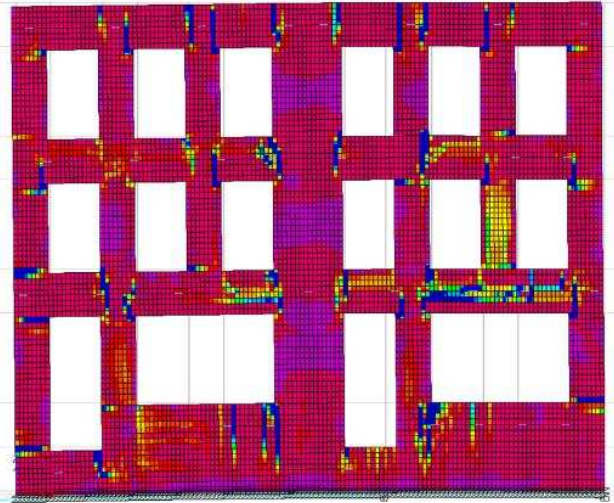

(a)

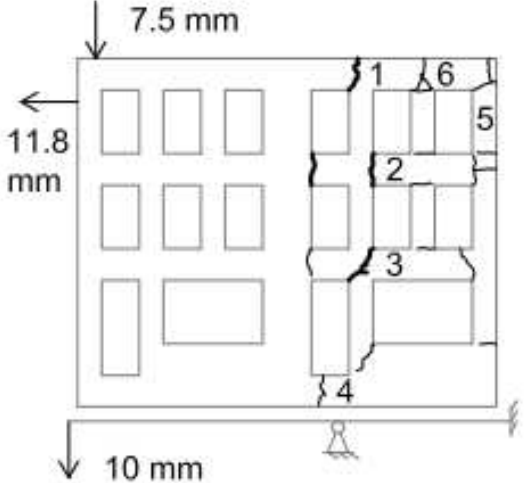

(b) 
Figure 9 : (a) maximum principal tensile strain from FE analysis and (b) crack pattern observed in the test

\subsection{Full-Scaled Building Tests}

Magenes et. al. [30] conducted a full-scale test on a two-storey URM building. The building was tested under quasi-static applied displacement. The overburden loads of $240 \mathrm{kN}$ were applied on the floors. The mean mechanical properties of the masonry are listed in Table 3.

Table 3 : Mechanical properties of tested masonry in Magenes' test [30]

\begin{tabular}{lllllll}
\hline $\begin{array}{l}\text { Density } \\
\left(\mathrm{kg} / \mathrm{m}^{3}\right)\end{array}$ & $\begin{array}{l}\text { Elastic } \\
\text { Modulus }(\mathrm{MPa})\end{array}$ & $\begin{array}{l}\text { Compressive } \\
\text { strength }(\mathrm{MPa})\end{array}$ & $\begin{array}{l}\text { Tensile } \\
\text { Strength }(\mathrm{MPa})\end{array}$ & $\begin{array}{l}\text { Initial } \\
\text { strength }(\mathrm{MPa})\end{array}$ & $\begin{array}{l}\text { Shear } \\
\text { friction }\end{array}$ & $\begin{array}{l}\text { officient } \\
\text { frion }\end{array}$ \\
\hline 1652 & 1491 & 6.2 & 0.04 & 0.23 & 0.58 \\
\hline
\end{tabular}

As shown in Figure 10, the inelastic capacity curve from FE analysis in terms of base shear vs. roof displacement is compared with the experimental results, which indicates good agreement. The envelope of the cyclic response is used for the sake of comparison. As an indicative example, the crack patterns at the peak base shear load level are shown in Figure 11 for the case with door walls. The numerical simulations were able to roughly indicate different failure mechanics observed during the course of testing for both cases including e.g. bed joint sliding, toe crushing and shear failure of piers and spandrels.
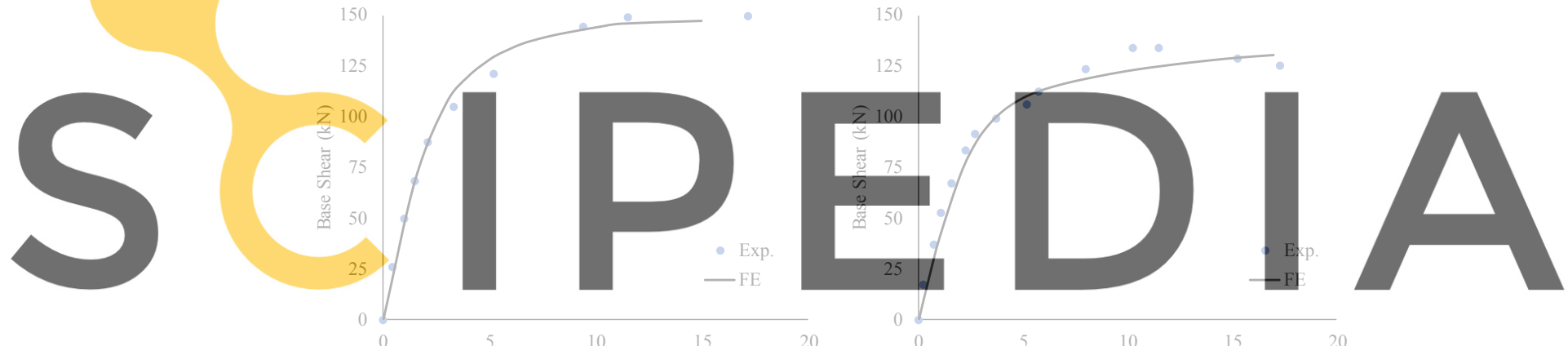

Register for free at https//www.scipediancom to download therversion without the watermark

(a)

(b)

Figure 10 : Base shear versus roof displacement of (a) door wall and (b) window wall

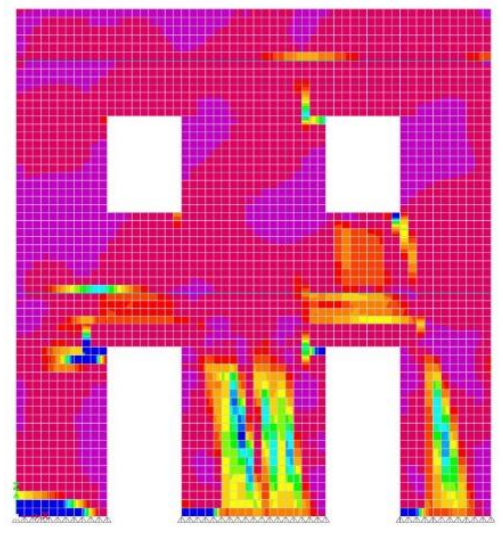

(a)

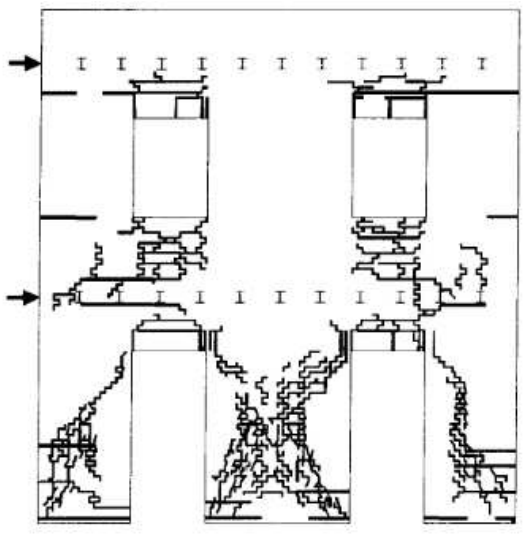

(b)

Figure 11: Peak load state of door wall: (a) maximum principal tensile strain at from FE analysis and (b) crack pattern observed in the test 


\section{CONCLUSIONS}

In this paper, a simplified method has been proposed for the finite element modelling of unreinforced masonry buildings based on a smeared continuum approach. It was established upon the framework of fibred shell elements with inelastic directional layers, and it was successfully implemented in ETABS software for nonlinear static (Pushover) analysis of buildings; however, it can be potentially applied to any commercial structural analysis software supporting the proposed framework. This method facilitates the modelling process of masonry buildings with complex geometries by using conventional shell elements with some rational yet simple material properties. It can eliminate some of the limitations and difficulties of the commonly used microelement (lumped plasticity) approaches, e.g. presumptive analysis, priori wall discretisation, and complicated modelling for irregular wall stacks and openings, while not significantly affecting the overall computational cost. The proposed approach serves as a practical solution and an easily accessible tool for the structural engineers worldwide to analyse full-scale structures, such as heritage buildings, and assess their structural performance under ultimate loading scenarios including earthquake. The accuracy of the FE model predictions has been verified against several experimental results and showed to be in good correlation. In summary, the proposed model not only can capture the overall structural response in terms of e.g. lateral load-displacement curve, but it can reasonably identify different failure modes in piers and spandrels and their associated cracking pattern as specified in some of the international standards and seismic provisions, e.g. ASCE and NZSEE.

\section{REFERENCES}

[1] A. M. D'Altri et al., "Modeling Strategies for the Computational Analysis of Unreinforced Masonry Structures: Review and Classification," Arch. Comput. Methods Eng., vol. 27, no. 4, pp. 1153-1185, Sep. 2020.

[2] A. PAGE, "THE BIAXIAL COMPRESSIVE STRENGTH OF BRICK MASONRY.," Proc. Inst. Civ. Eng., vol. 71, no. 3, pp. 893-906, Sep. 1981.

[3] K. Beyer, "Peak and residual strengths of brick masonry spandrels," Eng. Struct., vol. 41, pp. 533-547, 2012.

[4] J. van Elk and D. Doornhof, "Material Characterisation Version 1.3 Report," 2016.

[5] J. A. Thamboo, "Material characterisation of thin layer mortared clay masonry," Constr. Build. Mater., vol. 230, p. 116932, 2020.

[6] T. Manzouri, M. P. Schuller, P. B. Shing, and B. Amadei, "Repair and retrofit of unreinforced masonry structures," Earthquake Spectra, vol. 12, no. 4. pp. 903-922, 1996.

[7] L. S. Hogan, I. Giongo, K. Q. Walsh, J. M. Ingham, and D. Dizhur, "Full-scale Experimental Pushover Testing of an Existing URM Building," Structures, vol. 15, no. March, pp. 66-81, 2018.

[8] M. Tondelli, M. Rota, A. Penna, and G. Magenes, "Evaluation of Uncertainties in the Seismic Assessment of Existing Masonry Buildings," J. Earthq. Eng., vol. 16, no. sup1, pp. 36-64, Jan. 2012.

[9] A. M. D’Altri, F. Messali, J. Rots, G. Castellazzi, and S. de Miranda, "A damaging blockbased model for the analysis of the cyclic behaviour of full-scale masonry structures," Eng. Fract. Mech., vol. 209, pp. 423-448, Mar. 2019.

[10] E. Minga, L. Macorini, and B. A. Izzuddin, "A 3D mesoscale damage-plasticity approach for masonry structures under cyclic loading," Meccanica, vol. 53, no. 7, pp. 1591-1611, 
May 2018.

[11] G. Maier and A. Nappi, "A theory of no-tension discretized structural systems," Eng. Struct., vol. 12, no. 4, pp. 227-234, Oct. 1990.

[12] D. Briccola, M. Bruggi, and A. Taliercio, "Analysis of 3D no-tension masonry-like walls," J. Mech. Mater. Struct., vol. 13, no. 5, pp. 631-646, Dec. 2018.

[13] H. R. Lotfi and P. B. Shing, "An appraisal of smeared crack models for masonry shear wall analysis," Comput. Struct., vol. 41, no. 3, pp. 413-425, Jan. 1991.

[14] J. Toti, V. Gattulli, and E. Sacco, "Nonlocal damage propagation in the dynamics of masonry elements," Comput. Struct., vol. 152, pp. 215-227, May 2015.

[15] P. B. Lourenço, Computational strategies for masonry structures, vol. 70, no. 08. 1996.

[16] T. Salonikios, C. Karakostas, V. Lekidis, and A. Anthoine, "Comparative inelastic pushover analysis of masonry frames," Eng. Struct., vol. 25, no. 12, pp. 1515-1523, 2003.

[17] R. Siano et al., "Numerical investigation of non-linear equivalent-frame models for regular masonry walls," Eng. Struct., vol. 173, no. June, pp. 512-529, 2018.

[18] CSI, "ETABS Analysis and Design of Building Systems." Computers and Structures Inc, Berkeley, California.

[19] CSI, "SAP2000 Integrated Software for Structural Analysis and Design." Computers and Structures Inc, Berkeley, California.

[20] J. Heyman, “The stone skeleton,” Int. J. Solids Struct., vol. 2, no. 2, pp. 249-279, Apr. 1966.

[21] K. Doherty, M. C. Griffith, N. Lam, and J. Wilson, "Displacement-based seismic analysis for out-of-plane bending of unreinforced masonry walls," Earthq. Eng. Struct. Dyn., vol. 31, no. 4, pp. 833-850, 2002.

[22] Federal Emergency Management Agency, "FEMA 440 Improvement of Nonlinear Static Seismic Analysis Procedures," Redwood City, CA, 2005.

[23] ASCE, Seismic Evaluation and Retrofit of Existing Buildings ASCE/SEI 41-17. 2017.

[24] NZSEE, The Seismic Assessment of Existing Buildings - Initial Seismic Assessment Part B. 2017.

[25] D. J. Sutcliffe, H. S. Yu, and A. W. Page, "Lower bound limit analysis of unreinforced masonry shear walls," Comput. Struct., vol. 79, no. 14, pp. 1295-1312, Jun. 2001.

[26] K. Chaimoon and M. M. Attard, "Modeling of unreinforced masonry walls under shear and compression," Eng. Struct., vol. 29, no. 9, pp. 2056-2068, Sep. 2007.

[27] European Committee for Standardization, "Eurocode 6: Design of masonry structures Part 1-1: General rules for reinforced and unreinforced masonry structures." 2005.

[28] G. Giardina, A. Marini, M. A. N. Hendriks, J. G. Rots, F. Rizzardini, and E. Giuriani, "Experimental analysis of a masonry façade subject to tunnelling-induced settlement," Eng. Struct., vol. 45, pp. 421-434, 2012.

[29] G. Giardina, A. V. van de Graaf, M. A. N. Hendriks, J. G. Rots, and A. Marini, "Numerical analysis of a masonry façade subject to tunnelling-induced settlements," Eng. Struct., vol. 54, pp. 234-247, 2013.

[30] G. Magenes, G. M. Calvi, and G. R. Kingsley, "Seismic testing of a full-scale, two-storey masonry building: Test procedure and measured experimental response," Exp. Numer. Investig. a brick Mason. Build. - Numer. Predict. Exp. Rep. 3.0 - G.N.D.T., no. January, pp. 1.1-1.41, 1995. 